\title{
XLVI. On certain molecular constants
}

\section{Frederick Guthrie}

To cite this article: Frederick Guthrie (1883) XLVI. On certain molecular constants, Philosophical Magazine Series 5, 16:101, 321-339, DOI: 10.1080/14786448308627441

To link to this article: http://dx.doi.org/10.1080/14786448308627441

册 Published online: 28 Apr 2009.

Submit your article to this journal

Џ Article views: 2

Q View related articles $₫$ 


\title{
LONDON, EDINBURGH, AND DUBLIN
}

\section{PHILOSOPHICAL MAGAZINE}

\author{
AND \\ JOURNAL OF SCIENCE. \\ [FIFTH SERIES.]
}

NOVEMBER 1883.

XLVI. On certain Molecular Constents. By Frederich Guthrie.*

[Plates IV. \& V.]

Path-density. Path-mass. Liquid Slabs. Metallic Diffusion.

§ 1. PATH-DENSITY.-For some years past I have been trying to make clear to myself and others the idea of path-density as distinguished from ordinary density. One is reluctant to introduce new conceptions into science unless they are called for by existing known facts, or unless they suggest the existence of unknown ones. The idea of path-density arose from the attempt to get an insight into the condition of the eommon surface of two media, and especially of that imperfectly understood condition of the surface of liquid masses, known as Surface-tension or Skin. The connexion between path-density and surface-tension will be shown in $\S \S 13,14$.

$\S 2$. If a given mass of matter alters its volume, it thereby alters its density. If a point or minute piece of matter which weighs a gram were to swell to the size of a cube centimeter, or if a cube yard of matter weighing a gram $\dagger$ were to shrink to the size of a cube centimeter, matter of unit density would

* The experimental parts of this paper were communicated to the Physical Society during the Session 1882-83.

+ I use the terms "gram as weight" and "gram as mass"indiscriminately. Phil. Mag. S. 5. Vol. 16. No. 101. Nov. 1883. 
be obtained (water at $4^{\circ} \mathrm{C}$.). Expressed generally,

$$
\mathrm{D}=\frac{\mathrm{M}}{\mathrm{V}} \text {. }
$$

\$3. (a) A cube centimeter of water at $4^{\circ}$ C. moves in a straight line at right angles to one of its faces at a uniform rate of 1 centimeter in 1 second. It traces out a path of unit density. This conception is perhaps put into a more useful form: $(\beta)$ A square centimeter of surface having the mass of 1 gram moves at the rate of 1 centimeter a second; its path is of unit density. The thickness of the surface is here nothing, and its density is infinite. More generally: $(\gamma)$ Unit pathdensity is made when a plane surface of area $\frac{1}{\mathrm{n}}$ centimeter, weighing $\frac{1}{\mathrm{n}}$ gram, moves with uniform velocity.

Perhaps this is clearer if we imagine an infinite series of square centimeter-gram-surfaces following one another at equal intervals of 1 centimeter apart, and moving at any velocity along a straight path at right angles to them. Then any cubic centimeter of such an infinite path will weigh 1 gram.

Returning to concrete examples:-

If $\mathrm{P} d$ denote path-density,

$\delta$ denote density (specific gravity),

$l$ denote the thickness in direction of motion (centimeter), $r$ denote rate (centimeter-second);

then

$$
\mathrm{P} d=\frac{l . \delta}{r} . . . \quad . \quad . \quad .
$$

$\$ 4$. The few following obvious deductions may serve as illustrations. $\mathrm{P} d=\delta$ when $\frac{l}{r}=1$; that is, when the space passed over by any point of the moving mass in a unit of time is the same as the length of the matter which passes through that point when the point is at rest. In other words, there must be no gaps. Moving continuous matter has a path of the same density as the matter itself.

$\S 5$. If the mass be at rest, the expression (1) becomes $\mathrm{P} d=\frac{0 \times \delta}{0}$, which, though of ambiguous form, here means that $\mathrm{P} d=\delta$. The two 0 's are equal, having been derived from rational diminution of $l$ and $r$. The same is true if $r$ and $l$ are both infinite.

It is clear, but must be especially noted, That the ratio between the path-densities $\mathrm{P} d_{a_{1}}$ and $\mathrm{P} d_{a_{2}}$ is the same whether those paths are generated by the single transit (in an eternity) of the masses $\mathrm{A}_{1}$ and $\mathrm{A}_{2}$ moving at the rates $\mathrm{r}_{1}$ and $\mathrm{r}_{2}$ respectively: 
or by an endless succession of masses $\mathrm{A}_{1}$ moving at the rate $\mathbf{r}_{1}$ at $a$ distance $\mathrm{d}$ apart, and an endless succession of masses $\mathrm{A}_{2}$ moving at the rate $\mathrm{r}_{2}$ at the same distance $\mathrm{d}$ apart: or by the same masses $\mathrm{A}_{1}$ and $\mathrm{A}_{2}$ returning at equal intervals with the velocities $\mathbf{r}_{1}$ and $\mathbf{r}_{2}$.

These statements may be illustrated as follows:-Let there be (Plate IV. fig. 1) an annular tube $b$ of 12 cub. centim. capacity, and let there be $1 \mathrm{cub}$. centim. of water at $a$. At whatever rate $a$ may pass round $b$, the density of the path is the same, namely $\frac{1}{12}$. If it move round at the rate of once in a second, let its path-density be $P d$. If, now, it moves round $n$ times in a second, then in expression (1) $r$ becomes $n r$, and $l$ becomes $n l$; so that $P d$ remains unchanged.

Again, if the tube $b$ be doubled in length, the path-density will be halved at whatever rate $a$ may move.

$\S 6$. When an irregularly* shaped mass of uniform density moves with uniform velocity in a straight line, the path is of uniform density longitudinally but varies in density transversely (like a sword-stick).

Taking the case of a triangle moving on its base (fig. 2, Pl. IV.), we have at once

$$
\frac{\mathrm{P} d}{\mathrm{P}} d_{b}=\frac{a}{b}
$$

The distances $a$ and $b$ are here indeed nothing more than the expression $l$ in $\S 3$, equation (1).

$\S 7$. If $l$ be constant, that is if the moving matter have equal thickness all over in the direction of its motion, variation in density at different parts will of course produce corresponding and proportional variation in the path-density.

It follows that a heavy sector of a circle of unit density revolving about the centre of the circle will give rise to a path which is of uniform density, and whose density is $\frac{\theta}{360^{\circ}}$, if $\theta$ be the angle of the sector. The shadow of such a disk is uniformly dense or the moving disk is equally transparent to light.

If a heavy line revolve about one of its ends, the density of the path, which is a circular surface, varies inversely with the distance from the centre. The shadow of such a revolving line (or narrow strip) varies in density according to the same rule.

$\$ 8$. The path-density of a heavy plane moving parallel to itself, as in $\$ 3(\beta)$, but inclined to its path at an angle $\theta$, is $\frac{\mathrm{P} d}{\sin \theta}$, if $\mathrm{P} d$ be, as before, the path-density, when the plane is at

* Any shape excepting a prism having parallel back and front faces. 2 A 2 
Fhil. Mag. S. 5. Vol 16. 11.7V.

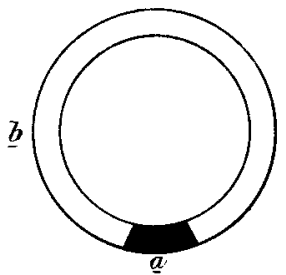

Fig. 1 .

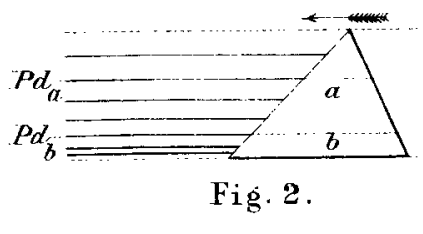

Fig. 2.

Fig. 4.

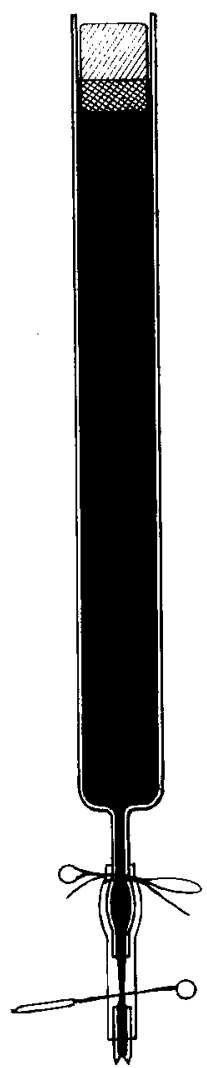

Fig. 6.
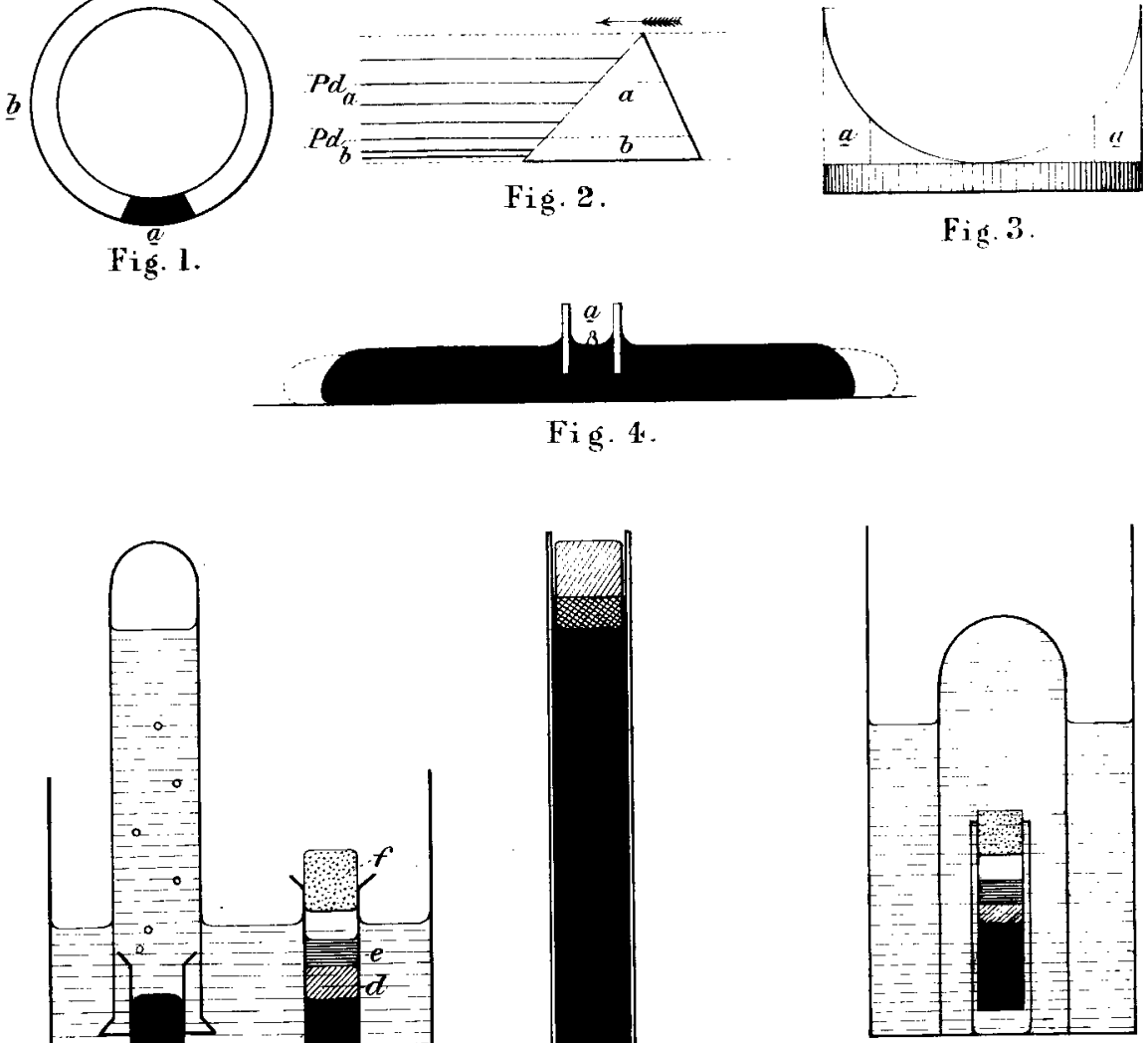

Fig. 7.

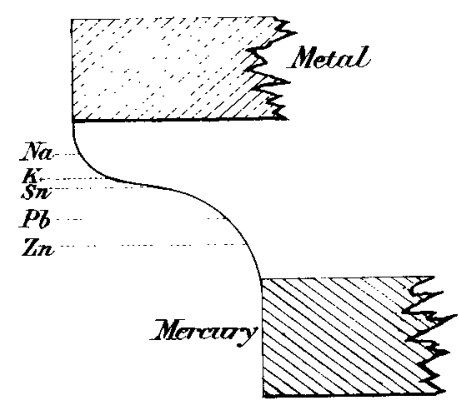

Fig. 8. 
right angles to the path. The sectional area of the path is of course proportionally less, being $\sin \theta$.

\$9. Path-mass.-For unit of path-mass it will be convenient to take the same conditions of motion as before $(\S 3)$, namely, a square gram-centimeter moving at the rate of 1 centimeter in 1 second at right angles to itself.

If two such plates follow one another in a second, the pathdensity and the path-mass are both doubled. If they are placed edge to edge in one plane and move with the unit velocity, their path-mass will be doubled. For the path has the unit density but double the volume of that generated by the single square. Just as in ordinary mass we have

$$
\mathrm{M}=\delta \mathrm{V}
$$

(where $\mathrm{M}=$ mass, $\delta=$ density, and $\mathrm{V}=$ volume), so here we have

$$
\mathrm{P}_{m}=\mathrm{VP}_{d} \text {. }
$$

Of course, if the path be maintained at uniform density by the passage of successive surfaces, the total mass will be infinite. But the mass per unit length is proportional to the sectional area of the path at right angles to it. And this is the case when a finite path is maintained at constant density by the to-and-fro motion of the surface or by its orbital return, as in $\$ 5$.

$\S 10$. However a mass of matter may rotate, however irregular it may be in shape or density, however it may change its shape or density, and whatever may be its velocity or change of velocity, its total path-mass is constant for the same timeinterval provided only its mass remains the same.

$\S 11$. If the earth's orbit be $300,000,000$ kilometers in diameter (a little more than 186,000,000 miles) and its diameter be 8000 miles, the height of a cylinder having the same volume as the earth and the same diameter is 5333 miles, or 8580.797 kilometers. It therefore appears that the mean orbit-density of the earth is $7 \cdot 761$ times the specific gravity of the earth, or, say, about 39 or 40 .

$\S 12$. If a single moving atom were enclosed in a box of fixed internal dimensions, the mean density of the gas constructed by it would be constant, however the atom might move. But if the atom move to and fro between opposite walls with acceleration, say harmonically, its path will be denser at its extremities and densest at the walls according to the law of sines, or as though the material area between a semicircle and its tangent had been compressed upon the tangent (fig. 3).

$\S 13$. The increased path-density caused by the retardation 
of solid matter towards the end of its harmonic excursions is visible with a vibrating rod whose excursions are many times longer than its thickness. Better with a long monochord wire. The shadow of such a wire shows most distinctly the increased path-density at its edges when it vibrates in a plane at right angles to the light. If such a cord be made to vibrate in a circular path, or if an upright rod be fastened excentrically to the top of a humming-top, the shadow is also graduated, being densest at the edges. Here we have really of course the projection of a circular path of uniform density on a tangent to the circle, precisely as in $\S 12$. The vibrating solids have skins.

$\S 14$. The hypothesis which I submit, and which is quite independent of the facts of the preceding paragraphs, is briefly that, when a mass of liquid has a free surface, while the internal particles have paths more or less free, those that strike the bounding surface never have free paths unless they strike it at such angles as enable them to escape as vapour. They are momentarily at rest; and however snall and elastic (in regard to the surface) they may be, they form a dynamic (ever renewed) skin, which in its turn acts as a check upon the passing particles, delays them, and so thickens their crowd.

There is arcordingly at all such surfaces an increased density due to diminished mean velocity; and it is this increased density which forms the so-called surface-tension or skin. Gases and vapours should have such skins at the bounding surface between themselves and liquids and solids; and perhaps it is for this reason that a solid has the power of what is virtually condensing a gas, even sometimes to liquefaction, upon its surface.

$\S 15$. Liquid Slabs.--Whether or not the hypothesis in $\S 14$ as to the cause of surface-tension be correct, and whether or not the terms surface-tension or skin be either of them satisfactory, it is convenient to adopt some such expression for the apparent toughness of the surfaces of liquids. When a little liquid is poured upon a flat horizontal surface which is not attacked by the liquid, a circular disk of liquid is formed, the shape of the edge of which has been very fully examined by Quincke and others. In most such cases, one of the most important factors is the specific relationship in the sense of adhesion between the solid and the liquid. In fact the question, like all questions of capillarity, involves density (and gravitation), cohesion, adhesion, and surface-tension. Such experiments show the relationship between two bodies as well as the physical attributes of one. Ahout twenty years ago I made an attempt to get rid of the factor adhosion, with partial 
success, by examining the size of a liquid drop. But I soon found that other factors, notably the shape of the solid bodies from which the dropping occurred, and the rate of dropping, introduced arbitrary conditions which removed the measurements from the class of simple physical constants.

$\$ 16$. The plan adopted in the following experiments is the endeavour to support a mass of liquid above a plane surface in such a way that no actual contact ensues, not even such as takes place between clean glass and mercury. If such can be done, it is clear that we shall have a circular flat slab with rounded edges, and into the shape of that slab the influence of adhesion by no means enters. If the thickness of the slab be found to be a constant, we shall have a constant as characteristic as density, and, like density, varying for the same mass only according to volume, such volume-change in our case being brought about by heat alone. Such slab-thickness has for its negative influence the action of gravity (density), for its positive the cohesion and surface-tension.

$\S 17$. The actual measurements of the slab-thickness I bave performed in two ways:-(1) by a spherimeter which, when used as such, gives results trustworthy to the $\frac{12}{10000}$ of an inch. But the upper of the two surfaces whose distance has to be measured being liquid, and the lower one not very hard, the spherimeter cannot be used by the method of touch. Accordingly I have measured the slab-thickness indirectly. A known volume of the liquid is poured on the surface, and teased into the circular form if it shows any noticeable departures from it. Four or five diameters are measured by means of a small horizontal cathetometer. The mean being taken, an allowance has to be made for the meniscus. This reduces the shape to the cylindrical, from which the thickness $h$ is deduced by means of the equation

$$
h=\frac{\mathrm{V}}{\pi r^{2}}
$$

§18. In regard to the actual apparatus:-Upon a thick round slab of paraffin, a foot in diameter and 4 inches thick, a massive foot of plaster is cast. The whole is placed on a three-screw levelling support. The surface of the paraffin is scraped into a true plane. When water was being examined, the surface of the paraffin was lightly powdered with lycopodium and the water poured on vertically from a fine opening. With some care a perfectly round slab of water 6 inches in diameter can be formed, which is so free to move that the greatest nicety of adjustment in the levelling-screws is necessary. Precisely the same arrangement can be adopted 
for mercury. But it was found that for the latter liquid a sheet of blotting-paper wetted and allowed to dry on a sheet of plate-glass gave results identical with those of the paraffin surface. The paper surface was used in some of the experiments. As to the allowance for the meniscus, it is clear that this is of less consequence with large slabs than with small ones. Indeed, with slabs a few inches in diameter the meniscus might be neglected. This was imperfectly shown in the case of mercury by adding exactly equal volumes to a small slab. After the slab had passed 2 inches in diameter, each additional volume produced a "parabolic" increase in the diameter. Data derived from this and from the measurement of an enlarged photograph of the edge gave me as a mean 2 millim. to be deducted from the diameter in the case of mercury. Assuming it to be the same for water, the error incurred, after making this reduction, could not in a 6 -inch slab be more than $\frac{1}{500}$ of the diameter. This would be negligible in the deduced thickness.

$\$ 19$. I give the following datum for mercury on account of the accidental coincidence of the experimental numbers with numbers easy of remembrance, excepting as to the temperature, which is, however, not far from the conventional temperature of $60^{\circ} \mathrm{F}$.

100 cub. centim. of mercury at $14^{\circ} \mathrm{C}$. has an extreme radius of 100 millim.

$$
h=\frac{100,000}{3 \cdot 1416 \times 99^{2}} ;
$$

thickness of mercury slab $=3 \cdot 248$ millim.

In the case of water it was found so difficult to get a nearly circular slab with 100 cub. centim., that only 50 were employed. The slab may then be teased into a circular form by means of a stick of paraffin covered with lycopodium.

50 cub. centim. of water at $14^{\circ} \mathrm{C}$. has an extreme radius of $54 \cdot 8$ millim.

$$
h=\frac{50,000}{3 \cdot 1416 \times(53 \cdot 8)^{2}} ;
$$

thickness $=5.50$ millim.

Glycerine* is a beautiful liquid in this respect. It is kept off from the paraffin surface by a very faint blush of lycopodium, and it travels very slowly. It can be got into a circular slab more easily than water; but, perhaps on account of its capillary action towards its lycopodium props, it is more persistent in its motion. In fact, unless there be hills of that sub-

$$
\text { * Commercial, "Price's." }
$$


stance to confront it, it rolls along (for that is the motion of a slab however large) and forms a "level," which requires a very steady support to avoid the notion that its motion is affected by the gravity of the observer.

50 cub. centim. of glycerine at $14^{\circ} \mathrm{C}$. has an extreme radius of 59 millim.

thickness $=4 \cdot 731$ millim.

$$
l=\frac{50,000}{3 \cdot 1416 \times(58)^{2}} ;
$$

$\$ 20$. Accordingly, taking the slab thickness of water as unity, we may begin a table which will at some future time assuredly be extended.

$$
\begin{aligned}
& \text { Specifie Slab-thickness }\left(\text { at } 14^{\circ} \mathrm{C} .\right) \text {. } \\
& \text { Water } \cdot=1.0000, \\
& \text { Glycerine }=0.8602, \\
& \text { Mercury }=0.5906 .
\end{aligned}
$$

These numbers may be, with instruction, considered in reference to the numbers in table vii. which concern the drop sizes of the same three liquids in the "Proceedings of the Royal Society,' 1864, p. 17 ["Recess"]. It will, I have no doubt, appear that in all cases the greater the drop-size the greater the slab-thickness. Water will, no doubt, again assert its singularity and exhibit the greatest slab-thickness.

$\$ 21$. Restrained as slabs are in their form by skin-tension as well as cohesion, it is found that the addition of a liquid which diminishes the former diminishes also the slab-thickness. Taking $25 \mathrm{cub}$. centim. of water at $14^{\circ} \mathrm{C}$., a slab was formed having 38 millim. corrected radius. This gives a thickness of $5 \cdot 51$ millim. Such a slab is unchanged if touched in the middle by a drop of glycerine. But on touching it with "glacial " acetic acid, it instantly aequires a corrected radius of 44 millim., or thickness of $4 \cdot 16$ millim. This means a diminution in thickness of very nearly 25 per cent., or one quarter. The question therefore presented itself, What is the slab-thickness of " glacial " acetic acid?

I reserve the results of my experiments in the direction of the relationship between the liquids and the alteration of skintension.

\$22. The mercury slab, like the water slab, has what virtually amounts to a skin; and it became interesting to examine the conditions of this skin or region of surface-tension. If lycopodium be strewn upon the surface of a mercury slab, and a little tin, zinc, or lead, or amalgam of these metals, be made to touch the slab in the middle, no noticeable disturbance takes place. But if such a slab be touched by an amalgam 
of $\mathrm{K}$ or $\mathrm{Na}$, the slab instantly expands, and the film of lycopodium-powder on its surface cracks radially, exposing the brilliant metallic surface, which is seen to be agitated over its whole extent. In a few seconds the slab contracts to its original size and the lycopodium cracks heal.

Does this extension of the slab depend upon the diminution of the cohesion of the mass of the mercury, or upon a surface effect?

$\S 23$. I frequently in my researches have had recourse to the fact, which I first described in the year 1863, that a little sodium added to mercury enables that metal to touch with positive capillarity motals which in its and their ordinary state are not wetted by the liquid metal. I here make use of the same fact. A platinum tube, 6 millim. in internal diameter and 2 centim. in height, is rubbed and soaked in some weak sodium amalgam, and then washed in several quantities of pure mercury. Placing such a tube vertically in the middle of a slab of mercury so that its lower edge is clear of the surface upon which the mercury slab rests, we have the condition shown in fig. 4. A little grain of sodium amalgam dropped into the platinum tube causes no immediate change; but in a time measurable by seconds, say 20 to 30 seconds, the slab starts on its expansion and reaches its maximum size, apparently immediately. It seems, then, that since the effect is not instantaneous, it is a surface effect. The effect when produced is due to an alteration of the surface between the tube and the outer portion of the slab. By dipping the platinum tube further down into the slab so as to be within $\frac{1}{50}$ of an inch of the bottom, I have found the effect to be distinctly delayed.

$\S 24$. The fact mentioned in $\$ 23$, that the release of the mercury skin-tension by sodium is brought about after a time, short indeed, but appreciable when introduced into the central part of a liquid slab inside the platinum tube, points to the existence of a true diffusion between the metals; and thị leads to the third part of this communication. For I have examined already a few such cases, which I will now describe, because I believe the subject of elementary diffusion has been neglected excepting in the case of gases, and even here but little is really known.

$\S 25$. Metallic Diffusion.-The metals potassium and sodium suggested themselves of course at once. They offer exceptional facilities for the determination of the composition of the mixture, when they have diffused through mercury, because the mere addition of water translates the alkaline metal into hydrogen. The neutralization of the alkalized water, say, by 
hydrochloric acid, and subsequent evaporization and weighing, give a control upon the hydrogen translation of the alkaline metal. The mercury is thereupon left nearly ready for weighing.

On the other hand, I have not yet been able to establish a column of mercury having an unlimited stock of pure cold alkaline metal above pure mercury at the same temperature below. I do not see the possibility of it. Granted that when such metals as tin, or lead, or gold, or silver dissolve in mercury heat may move, such movement of heat is, I should think, swamped in its power of causing convection-currents by the conductivity of the mass. But in the case of the alkaline metals the first contact of the two metals is accompanied by so much heat that the conditions obtainable with otber metals are here far more difficult. Perhaps mercury and sodium brought into contact at a temperature far below the freezing-point of mercury might give the required starting-point. If their contact were real and the elevation of temperature very gradual and well controlled, we might have a trustworthy condition; but scarcely at a single temperature.

Such a condition would represent a certain fixed sodium potential (not infinite, because the sodium has to be disintegrated), on the one hand, and a lower, but not zero, on the other; and between the two the integral of the resistances of the various amalgams after the first contact.

$\$ 26$. This being so, I elected to employ sodium amalgam and potassium amalgam rather than the free metals.

On mixing sodium with mercury, the two combine with great energy and liberate so much heat as to point to a loss of volume. Is this loss of volume, if it take place under any circumstance, so great as to give rise to an amalgam having a greater density than mercury itself?

If $\frac{m_{1}}{v_{1}}$ be the density of mercury and $\frac{m_{2}}{v_{2}}$ that of sodium, and if $v_{3}$ be the volume of the amalgam, then the density of the amalgam would be equal to that of the mercury, if

or

$$
\frac{m_{1}+m_{2}}{v_{3}}=\frac{m_{1}}{v_{1}}
$$

$$
v_{3}=v_{1}\left(1+\frac{m_{2}}{m_{1}}\right) \text {. }
$$

If $v_{3}$ should be less than this for any ratio between the constituents, the convection-currents of sodium would at all events begin to flow down if such an amalgam were at the top of the mercurial column. 
On this point, without making a study of the specific gravity of alloys of sodium of different strengths, I have satisfied myself that, as long as the amalgam is liquid, it is lighter than mercury. This is easily shown by introducing mercury into one limb and the various liquid amalgams of sodium into the other limb of a long U-tube: whereupon the pure mercury always prevails in weight. Now when a solid amalgam of sodium is brought into contact with mercury, heat may be either set free or absorbed. Chemists will understand me if I remind them that $a$ pounds of water mixed with $b$ pounds of chloride of calcium will give a body which will set free or absorb heat according as $a$ is greater or less than $x$.

$\S 27$. Accordingly I made a pound or two of a sodium amalgam of such a strength as to be solid at the atmospheric temperature. This was beaten up in an iron mortar as it cooled. Putting some of this into a porcelain crucible, plunging it into water containing a few drops of hydrochloric acid, and collecting the hydrogen, it was found that after a day or two, if the analgam was occasionally stirred, all evolution of hydrogen ceased; the volumes, reduced to dry hydrogen at $0^{\circ} \mathrm{C}$. and 760 millim., were $\left\{\begin{array}{l}156 \\ 128\end{array}\right\}$ cub. centim. The mercury, after drying, was found to weigh $\left\{\begin{array}{l}15 \cdot 1096 \\ 13 \cdot 7841^{\circ}\end{array}\right.$. This gives the percentage of the amalgam which $I$ shall call Am amalgam:-

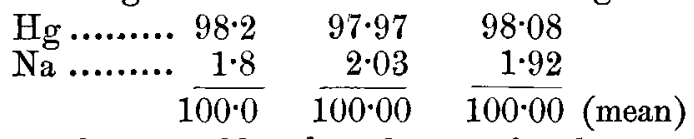

The ideal amalgam would perhaps be one of such a composition that heat would neither be set free nor absorbed on further mixing with mercury. But such an ideal condition could only be ideal in its beginning, and, I think, disturbances due to this cause are insensible in comparison with other sources of error. The above amalgam when stirred with mercury may reduce its temperature as much as $5^{\circ} \mathrm{C}$.

I am informed that sodium may contain a large quantity of hydrogen. I am not called on to discuss the experiments (not my own) upon which this rests; but I think that any considerable quantity would be expelled on amalgamation. Perhaps the glow or blush to be described immediately and in $\S 28$ is due to the escape of residual hydrogen at the released tensionsurface of the mercury.

The first experiment in regard to the diffusion of sodium out of this amalgam into mercury was of course a qualitative one. A U-tube (fig. 5, Pl. V.) was made of glass tube of $\frac{1}{2}$ inch internal diameter - the one limb, $A$, being about 3 inches and the 
Phil Mag. S. 5. Vo . 16.13.V.

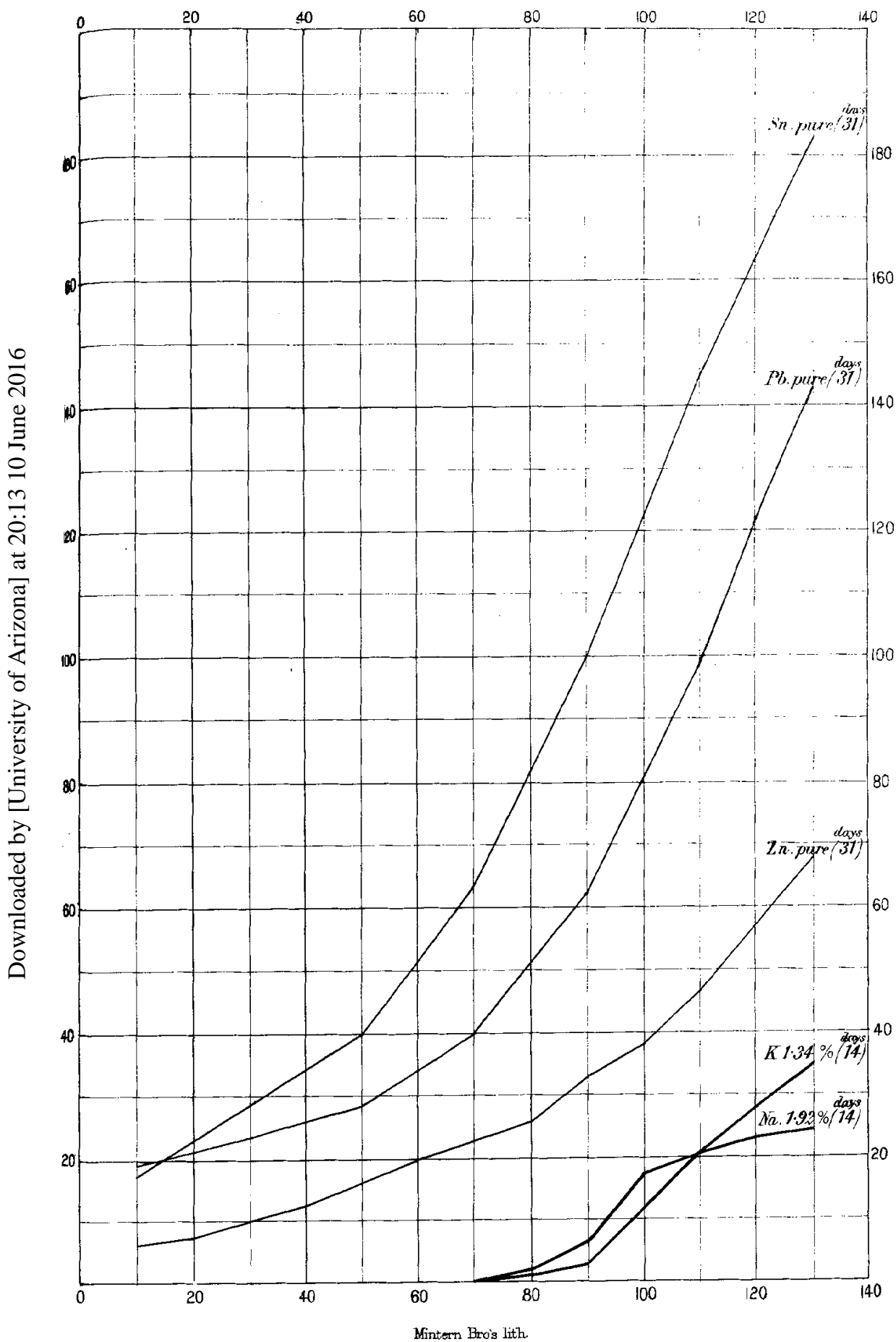


other, B, about $2 \frac{1}{2}$ inches long, reckoned from the inner bend $a$. This was fastened into a mass of fusible metal foot to give stability. The U-tube was dried perfectly under the ordinary aircondition, and received pure dry mercury, which stood in both limbs at a height of about 22 inches (reckoned from $a$ ). The whole was placed in a flat-bottomed vessel $g$ containing a little melted paraffin, and then upon an immovable slab, to which it was stuck by a few drops of paraffin. The vessel $g$ then received water slightly acidulated with $\mathrm{HCl}$ so as to cover the mercury in the shorter limb, and reach about $\frac{1}{4}$ inch above the edge of the glass tube on that side. A test-tube filled with similarly acidulated water was inverted over the shorter limb. Upon the surface of the mercury in A about 15 grams of the amalgam A $m$ was placed; this was covered with petroleum, and the tube was plugged with cotton-wool.

Immediately after introducing the sodium amalgam a kind of frosted appearance is seen on the immediately lower parts of the mercury and glass surface in A. This appearance, which is a blush of bubbles, creeps downwards with strange rapidity, reaching the bend, say $2 \frac{4}{10}$ inches, in a quarter of an hour.

In about 30 hours, bubbles of hydrogen appear at the surface of the mercury in $\mathrm{B}$ and collect in the pneumatic tube. Such evolution continues sensible for about a month. After two months such evolution ceased, the contents were emptied ont, thereby being of course mixed, and no further evolution of hydrogen could be detected.

Such a method of experimentation is, however, far from quantitative, because, when the sodium has diffused down through $\mathrm{A}$ as far as $a$, it will, being lighter than mercury, rise through $\mathrm{B}$ and cause whirls.

The ideal condition of such diffusion would be of course similar to the ideal condition of heat- or electrical transference, where one may have a given potential at one end of the column, and a given lower one, fancifully called zero, at the other.

Perhaps this condition is to be attained with the greatest practical completeness by the simple long vertical column.

$\S 28$. Three glass burettes were made, about a foot in length and an inch in internal diameter. They were drawn out sharply at the bottom into capillary tubes, upon which pressure-taps were fixed in the ordinary way. These were nearly filled with pure mercury. A little of the mercury was allowed to run through so as to fill the capillary and caoutchouc tube.

Upon a tube so prepared and filled, about 15 grams of the amalgam $\mathrm{Am}$ were placed. The amalgam was thereupon covered liberally with petroleum; and the top of the tube was 
slightly corked. Instantly clouds of minute bubbles began to make their appearance between the mercury and the glass. In half an hour the whole column appeared frosted (see $\$ 27$ ). On drawing off a measure, say $\frac{1}{13}$ of the whole, from the bottom after two or three hours, no appreciable amount of hydrogen was to be got from it.

Accordingly the tube was reemptied, cleaned, dried, and refilled. The amalgam $(\mathrm{A} m)$ was then allowed to rest upon the top for 14 days and nights in an undisturbed and steady place, where the temperature ranged from $13^{\circ}$ to $18^{\circ} \mathrm{C}$. At the end of this time the amalgam was drawn off. The drawing off was effected as follows:-A little block of paraffin was hollowed so as to have a smooth cavity of the capacity of about $\frac{1}{13}$ of the tube in fig. 6 . The edge was ground flat, and a flat slab of paraffin served as a cover. The amalgam was drawn into this very slowly so as to stand above the edge; the slab being then pressed down, a unit volume was entrapped. This being transferred to a porcelain capsule, the few drops of overflow were returned to the unit measure, which was again filled up, and so on. The six lowest measures (each about $\frac{1}{13}$ ) did not show a trace of hydrogen. The seven higher ones evolved hydrogen in the quantities shown in the following table, in which the actual weights of the mercury are reduced to 100 , the cub. centim. of hydrogen being recalculated and reduced to dry hydrogen at $0^{\circ} \mathrm{C}$. and 760 millim. It appears that in 14 days the sodium had penetrated down a little more than halfway, say 7 inches, in quantity appreciable.

I put now these results in such a form that they may be as far as possible immediately comparable with the results obtained by other metals. They come out as follows:-

\begin{tabular}{|c|c|c|c|}
\hline Per cent. Na. & $\mathrm{Hg}$. & & Na. \\
\hline$\cdot 0035 \ldots \ldots \ldots \ldots$ & 100 & and & .0035 \\
\hline$\cdot 0178 \ldots \ldots \ldots \ldots$ & $"$ & $\eta$ & $\cdot 0178$ \\
\hline$\cdot 0665 \ldots$ & " & 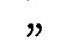 & $\cdot 0666$ \\
\hline$\cdot 1769 . \ldots \ldots \ldots . .$. & ", & " & $\cdot 1772$ \\
\hline •2034... & ", &, & $\cdot 2038$ \\
\hline$\cdot 2295 .$. & 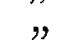 & 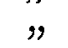 & $\cdot 230$ \\
\hline 2414. & $"$ & $"$ & $\cdot 242$ \\
\hline
\end{tabular}

$\$ 29$. A potassium amalgam prepared in a similar manner was found, when analyzed as in $\$ 27$, to have the composition 1.34 per cent. of $K$. About the same quantity of this was put into the same tube as had been used for the Na, under, as far as possible, the same conditions.

Reducing the evolved $\mathrm{H}$ to $0^{\circ}$ and 760 , as before, it was found that the 13 volumes of the column (all of which were 
nearly equal except the last, which, instead of about 84-82 grams of mercury, only held about 52 , for this was the drainage from the amalgam), had the composition:-

Per cent. of $\mathrm{K}$.
0.00082
$\cdot 0038$
$\cdot 0146$
$\cdot 0331$
$\cdot 1185$
$\cdot 2061$
$\cdot 2811$
$\cdot 3490$

As. to the comparison between $\mathrm{Na}$ and $\mathrm{K}$, we need only contemplate the potential difference between 1.92 and 1.34 respectively.

With regard to the frosted appearance mentioned in $\$ \S 27$, 28 , it can scarcely be doubter that the minute bubbles which compose it are hydrogen, due to the film of water or vapour on the glass. But while this appearance travels at the rate of at least one foot an hour, there is no sensible quantity of $\mathrm{Na}$ to be found at even a lesser depth after fourteen days. The effect must therefore be a surface-effect, and be of the same order as the effect described in $\S 22$, where the mercuryslab expands when touched by sodium amalgam, on account of the metals spreading almost instantaneously over its surface and enfeebling its skin. The condition actually set up in the mercury column is probably this:-A minute film of sodium spreads downwards between the mercury and the glass : this decomposes the water on the glass, and so clothes the glass with a film of minute hydrogen bubbles, and the mercury strface with a film of caustic soda, which latter is in absolute contact with the mercury surface. It is a question whether the sodium film is less than, equal to, or more than sufficient to decompose the water-probably more. At all events it is so minute as not to exhibit itself in any chemical reaction. The spectroscopic reaction here has no significance.

The curves $\mathrm{Na}$ and K, Plate IV., which represent these experiments graphically, are not directly comparable with the curves $\mathrm{Sn}, \mathrm{Pb}$, and $\mathrm{Zn}(\S 31)$ in the same plate, because in the case of $\mathrm{Na}$ and $\mathrm{K}$, for reasons given in $\S 25$, it was found necessary to start with an amalgam, and indeed with one containing only about 2 per cent. of sodium. The time in the case of the Na and $K$ amalgams was also only a little less than half that occupied in the diffusion of $\mathrm{Zn}, \mathrm{Pb}$, and $\mathrm{Sn}$.

$\S 30$. The rapid penetration of zinc by mercury suggested the question whether, when an amalgam of an alkaline metal 
was presented to zinc, the mercury would penetrate the zinc and carry the alkaline metal with it. Accordingly the above potassium amalgam was introduced into a hollow cylinder of cast zinc, 17 millim. internal, and 21 millim. external diameter (thickness 2 millim.), 45 millim. external height, 35 millim. internal height ( 10 millim. thickness of bottom). The amalgam was scraped upon the zine so as to ensure contact, and then covered with petroleum. The zinc cylinder was thereupon corked up and covered with paraffin. It was placed in a beaker of distilled water and covered with a tube of water according to fig. 7. After two months' standing at a uniform temperature of about $15^{\circ}$, scarcely a pin's-head volume of gas had collected in the top of the tube. Abundance of the semiflocculent fine oxyhydro-carbonate had collected on the zinc and at the bottom of the beaker. That part on the zinc was rubbed off the zinc with an ivory blade, and, together with the sediment in the beaker, dissolved in hydrochloric acid overneutralized with ammonia and sulphide of ammonium. After separation of the $\mathrm{Zn}$, no trace of $\mathrm{K}$ conld be found. No potassium had found its way through the zinc. Perhaps a more remarkable fact still is this, that on scraping about a gram of the solid metal from the outside of the zinc cylinder, not a trace of mercury could be found in it. Not only, therefore, did the alkaline metal fail to follow the mercury into the zinc, but it prevented the mercury from entering the zinc. Compare this with $\$ 32$, where the cylinder of zinc is literally "slaked" by the mercury.

\$31. Cylinders of zinc, lead, and tin were cast, an inch and a quarter long and $\frac{7}{8}$ inch in diameter. These were floated on the mercury contained in the tubes described in $\S 28$. The quantity of the mercury in each tube was such that it stood at the same height, reckoning from the bottom of each cylinder. The burettes had been previously lashed to massive stands, cork buffers being interposed between the tubes and the stands. The three were placed side by side on a slab let into the wall, and were protected as much as possible by cloths from sudden changes of temperature. The mean temperature was $15^{\circ} \mathrm{C}$. The experiments lasted a month, and the extreme range of temperature was from $13^{\circ} \mathrm{C}$. to $17^{\circ} .5 \mathrm{C}$.

At the end of the month (31 days) the mercury was run off from the bottom very slowly and discontinuously into the paraffin vessel described in $\$ 28$; so that, with the exception of the top quantities, the volumes of the successive portions were very nearly the same. With regard to the top quantities, it is clear that, since the metals float at different depths in the mercury, the surfaces of contact are not the same in the 
several cases; and therefore these top, or richest, amalgams can scarcely be compared. Again, the shape of the bottom of the tube with its capillary \&c. puts the lowest or poorest out of court. But as the contents of the lower, irregular part of the tube is not more than a third of the volume of the unit measure, it is only the very lowest amalgam that need be rejected.

In each case there were twelve full unit vessels drawn off, and in each case a fraction of a thirteenth, which last contained the drainage from the metal.

Through the kindness of Dr. Hodgkinson a number of these amalgams were analyzed in the chemical laboratory by Messrs. Adie, Gahan, and Grange, to whom I am therefore indebted. These three gentlemen analyzed the zinc, lead, and tin amalgams respectively. The metals were determined in the following manners:-

Lead.- The amalgam dissolved in nitric acid and evaporated with sulphuric acid, and the residue either ignited directly or after washing with dilute alcohol (as sulphate of lead).

Tin.-The amalgam dissolved in nitric acid, evaporated to dryness, and ignited (as metastannic acid).

Zinc.-( $\alpha$ ) By dissolving in nitric acid, evaporating to dryness, and igniting ; or $(\beta)$ by separating the mercury as sulphide and the zinc as sulphide, and igniting (both as oxide of zinc).

\$32. In Table I. the results of such determinations are given, so that the proportion of the errors of analysis may be compared with the true diffusion in each, and the difference of diffusion in the three cases.

At the end of the experiment the cylinders of tin and lead presented nothing remarkable in appearance. On standing a couple of months the upper part of the lead cylinder has become as hard as zinc, though there is no sensible deformation. The zinc cylinder swelled considerably in the tube; and when left to itself afterwards, though drained from the mercury, it continued to swell and crack, and ultimately fell to pieces like a "lime-light" lime cylinder when slaked. Two cones with their apices towards the centre of the cylinder were formed at top and bottom; the cracking otherwise was for the most part in radial planes.

In Plate $V$. the percentages of metal in the several amalgams of the three metals are given graphically, and without rounding off or other interpolation. The abscissæ reckoned from the left are distances from the bottom; the ordinates are the corresponding percentages of the respective metals. 
TABLe I.

\begin{tabular}{|c|c|c|c|c|c|}
\hline & Zinc. Per cent. & Lead. P & Per cent. & Tin. $\mathrm{F}$ & Per cen \\
\hline 1 (bottom)........ & $\left\{\begin{array}{l}0.064 \\
0.062\end{array}\right\} 0.063$ & $\left\{\begin{array}{l}0 \cdot 188 \\
0 \cdot 204\end{array}\right\}$ & $0 \cdot 196$ & $\left\{\begin{array}{l}0 \cdot 13 \\
0 \cdot 21 \\
0 \cdot 174\end{array}\right\}$ & $0 \cdot 171$ \\
\hline $2 .$. & $\left\{\begin{array}{l}0.076 \\
0.080\end{array}\right\} 0.078$ & & & & \\
\hline $3 . \ldots \ldots \ldots \ldots \ldots$ & ................ & $\left\{\begin{array}{l}0.243 \\
0.225\end{array}\right\}$ & 0.234 & $\left\{\begin{array}{l}0 \cdot 28 \\
0.30\end{array}\right\}$ & 0.29 \\
\hline 4. & $\left\{\begin{array}{l}0.126 \\
0.117\end{array}\right\} 0.122$ & & & & \\
\hline $5 . .$. & $\ldots \ldots \ldots \ldots$ & $\left\{\begin{array}{l}0.303 \\
0 \cdot 274\end{array}\right\}$ & 0.289 & $\left\{\begin{array}{l}0.38 \\
0.41\end{array}\right\}$ & $0 \cdot 40$ \\
\hline 6. ......... & $\left\{\begin{array}{l}0.214 \\
0.183\end{array}\right\} 0.199$ & & & & \\
\hline $7 \ldots$ & ............... & $\left\{\begin{array}{l}0.402 \\
0.403\end{array}\right\}$ & 0.403 & $\left\{\begin{array}{l}0.63 \\
0.62\end{array}\right\}$ & 063 \\
\hline 8. & $\left\{\begin{array}{l}0 \cdot 254 \\
0.266\end{array}\right\} 0 \cdot 260$ & & & & \\
\hline 9. ...... & $\left\{\begin{array}{l}0.337 \\
0.338 \\
0.325\end{array}\right\} 0.333$ & $\left\{\begin{array}{l}0.609 \\
0.646\end{array}\right\}$ & $0 \cdot 628$ & $\left\{\begin{array}{l}0 \cdot 99 \\
1.01\end{array}\right\}$ & - 1.00 \\
\hline $10 .$. & $\left\{\begin{array}{l}0 \cdot 408 \\
0 \cdot 365\end{array}\right\} 0 \cdot 387$ & & & & \\
\hline 11. & $\left\{\begin{array}{l}0 \cdot 468 \\
0 \cdot 454\end{array}\right\} 0^{\cdot} 461$ & $\left\{\begin{array}{l}1 \cdot 03 \\
0 \cdot 94\end{array}\right\}$ & $0 \cdot 99$ & $\left\{\begin{array}{l}1 \cdot 68 \\
1.41 \\
1.25\end{array}\right\}$ & $1 \cdot 45$ \\
\hline 12. & $\left\{\begin{array}{l}0.573 \\
0.569\end{array}\right\} 0.571$ & & & & \\
\hline 13 (top). & $\left\{\begin{array}{l}0.618 \\
0735\end{array}\right\} 0.677$ & $\left\{\begin{array}{l}1 \cdot 38 \\
1 \cdot 47\end{array}\right\}$ & $1 \cdot 43$ & $\left\{\begin{array}{l}1.86 \\
1.87 \\
1.76\end{array}\right\}$ & $1 \cdot 83$ \\
\hline
\end{tabular}

§33. It appears accordingly that the three metals lead, tin, and zinc, all of which and all of whose amalgams are lighter than mercury, diffuse downwards through this latter metal in such a fashion that they appear, after a month's interval, in appreciable quantity at a depth of a foot beneath the surface when the temperature is about $16^{\circ}-17^{\circ} \mathrm{C}$. With regard to this latter point, as to temperature, I suppose that mercury is so good a conductor of heat that the influence

Phil. Mrg. S. 5. Vol. 16. No. 101. Nov. 1883. 2 B 
of convection-currents is at least as inconsiderable as in the experiments which have been performed for determining the diffusion of soluble salts in water. It is scarcely worth while amusing oneself by dividing these diffusion percentages by the so-called "atomic weights" of the metals. A more serious consideration might be the result of the division of the diffused weight by the specific gravity of the metal. Comparing the numbers of the group $\mathrm{Sn}, \mathrm{Pb}$, and $\mathrm{Zn}$ with one another, we may remember that the metals are all cast, and therefore so far indefinite in structure. This may be especially the case with zinc, which cracks and thereby allows the mercury to rise by capillarity and so enrich itself, and generally set up conditions of amalgamation which I do not care to trace, for I do not see my way through.

As to the comparison of the alkaline group with the $\mathrm{Sn}, \mathrm{Pb}, \mathrm{Zn}$ groups, such comparison must be vague, for the reason that the $\mathrm{K}$ and $\mathrm{Na}$ are employed as amalgams (as though one would study the diffusion of nitre into water by employing a solution of nitre containing only 2 per cent. of the anhydrons salt); whereas the $\mathrm{Sn}, \mathrm{Pb}$, and $\mathrm{Zn}$ are use with what was supposed to be a sufficient supply of pure 100per-cent. metal. But this imperfection of these conditions is manifest if we remember that while the solid metal melts and dissolves downwards, the liquid mercury rises. Accordingly there is, after the first instant of contact, supposing the metals diffuse, no constant metallo-motive force in the same place.

$\S 34$. I conclude therefore that the general curve of amalgamation, and therefore of alloyage, and therefore perhaps of elementary atomic and molecular diffusion generally, is of the kind shown in fig. 8. In the case of $\mathrm{Na}$ almost the complete curve was obtained; whereas in the case of $\mathrm{Zn}$ the point of contriflexure had not been reached. The very fact that the $\mathrm{K}$ and $\mathrm{Na}_{2}$ curves are more complete, in this fashion, than the $\mathrm{Pb}, \mathrm{Zn}$, and $\mathrm{Sn}$, prove to my mind that $\mathrm{K}$ and $\mathrm{Na}$ have a far greater diffusive energy than the heavier metals examined. And although in this case the percentage of metal actually found at a given depth was in all cases much less than the percentages of the heavier metals, it will be borne in mind that, while the latter were fewer and had acted for thirty-one days, the former were amalgams containing less than 2 per cent. of the metal. Comparing $\mathrm{K}$ with $\mathrm{Na}$, I do not think we can draw any conclusion beyond the rather negative one, that the superior diffusive faculty which seems to be the property of $\mathrm{K}$ salts in regard to water does not evidence itself, if it exist, when that metal and sodium are compared in respect to their diffusion in mercury. I am far from asserting that 
such preeminence may not exist; but I do not think that it is here made conspicuous.

My friend Prof. Chandler Roberts has for a long time been engaged in studying the diffusion of melted metals, and the matter has been a subject of frequent conversation between us. I await with great interest the details of his experiments. The relative dates of our publication have no relation to the dates of our experiments.

XLVII. On Laplace's Theory of Capillarity.

By A. M. Worthington, M.A.

To the Editors of the Philosophical Magazine and Journal. Gentlemen,

'THE appearance of Lord Rayleigh's paper on Laplace's 1 Theory of Capillarity encourages me to send you some remarks on the same subject which I had prepared some months ago in connexion with work on capillarity on which $I$ have been engaged. I should be glad, however, that it should appear on the present occasion, as I think it may be of some use in explaining, rather more explicitly than Lord Rayleigh attempts to do, how the misconception of Laplace's quantity $K$ has arisen-a misconception which has become of almost historical importance in connexion with this subject.

The object with which Laplace sets out is to explain the fact that the hydrostatic pressure in a liquid just below a curved surface differs from the hydrostatic pressure just below a plane surface by an amount depending on the curvature of the surface.

He gives the accompanying figure, representing a vertical section of a capillary tube $\mathrm{NE}$ plunged in a vessel $\mathrm{AC}$ containing a liquid which wets the tube.

$\mathrm{VRZO}$ represents an infinitely thin canal or filament of the liquid whose cross section is taken as the unit of area, and which meets the plane surface at $\mathrm{V}$ and the curved surface at its lowest point $O$. On the assumption that the fluid is of uniform density throughout, and that between any pair of ele-

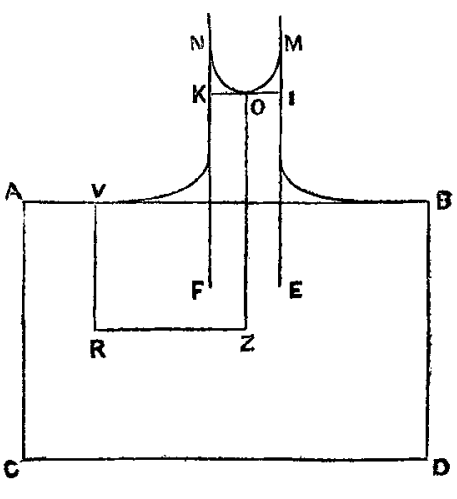
mentary volumes of it there is an attraction which is a function 